\title{
CNS fluid and solute movement: physiology, modelling and imaging
}

\author{
Hazel C. Jones ${ }^{1 *}$, Richard F. Keep ${ }^{2}$ and Lester R. Drewes ${ }^{3}$
}

In 2018, we invited readers of Fluids and Barriers of the CNS to contribute to a Thematic Series on aspects of fluid and solute movement into, within, and out of the brain. This subject has important implications for neurological diseases such as stroke, Alzheimer's disease (AD), idiopathic intracranial hypertension (IIH), normal pressure hydrocephalus (NPH) and syringomyelia. It is also an important factor in the delivery and distribution of pharmaceutics for disease treatment.

The submitted papers covered a variety of themes. One focused on cerebrospinal fluid (CSF) secretion or flow within the ventricles and subarachnoid spaces (SAS). Another theme centred on the controversial subject of perivascular flow around penetrating blood vessels using mathematical modelling. A third concerned movement of fluid and solutes through the brain interstitial space: a topic of great interest but difficult to study experimentally.

Advances in imaging have provided new insights into fluid and solute movement in the CNS. Techniques for improved resolution in magnetic resonance imaging (MRI) are enabling a better understanding of factors affecting CSF flow. For example in normal subjects, forced abdominal breathing had a larger effect on CSF flow than thoracic breathing especially in the spinal cord SAS, with inspiration resulting in upward flow [1]. Another study [2] demonstrated that in the cerebral aqueduct, the cardiac pulse had a larger effect on CSF velocity than the respiratory pulse, but the reverse was true for displacement volume. These studies in normal subjects can set the baseline for improved diagnosis of

\footnotetext{
*Correspondence: hazelcjones@btinternet.com

${ }^{1}$ Gagle Brook House, Chesterton, Bicester OX26 1UF, UK

Full list of author information is available at the end of the article
}

abnormal CSF dynamics in disease. For example, flow velocity and displacement volume were both increased in the aqueduct of a group of NPH patients but were reduced after shunt surgery [3]. Another study [4] found that both NPH and AD patients had similar but abnormal aqueduct CSF pressure gradients. However, the velocity was very variable in NPH patients and not abnormal in AD. After a series of consecutive lumbar drains, CSF compliance and cerebral perfusion pressure increased in IIH patients with raised intracranial pressure [5]. Although this invasive technique precludes a study with control subjects for comparison, it could be extended to predict treatment response. Another promising approach for modulating CSF dynamics in disease is to target secretory mechanisms in the choroid plexus, although this becomes very complex when considering the number of potential targets [6], especially when a large number of genes were shown to be altered in choroid plexus tissue from AD patients [7].

In vitro models of the CSF system are also being used increasingly to delineate CSF dynamics and to study pathological conditions. A 3D-model of the SAS was constructed from meningoepithelial cells and exposed to different flow conditions [8]. Abnormal CSF flow and hypoxia resulted in significant changes in expression of genes from the cultured cells involved in extracellular matrix composition, the endosome-lysosome system, and mitochondrial energy metabolism. A constructed model has been developed to investigate CSF flow and compliance during pathological disturbances [9], and a mathematical model was used to predict that jugular vein collapse reduces the fall in intracranial pressure when moving to upright posture and makes a significant contribution to mitigate the postural increase in intracranial compliance [10]. To assist research into diagnosis

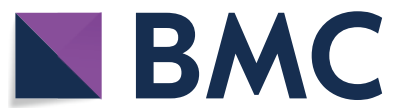

(c) The Author(s) 2020. This article is licensed under a Creative Commons Attribution 4.0 International License, which permits use, sharing, adaptation, distribution and reproduction in any medium or format, as long as you give appropriate credit to the original author(s) and the source, provide a link to the Creative Commons licence, and indicate if changes were made. The images or other third party material in this article are included in the article's Creative Commons licence, unless indicated otherwise in a credit line to the material. If material is not included in the article's Creative Commons licence and your intended use is not permitted by statutory regulation or exceeds the permitted use, you will need to obtain permission directly from the copyright holder. To view a copy of this licence, visit http://creativeco mmons.org/licenses/by/4.0/. The Creative Commons Public Domain Dedication waiver (http://creativecommons.org/publicdomain/ zero/1.0/) applies to the data made available in this article, unless otherwise stated in a credit line to the data. 
and the administration of therapeutics, a 3D geometric and hydrodynamic model of the spinal subarachnoid CSF was constructed from high resolution MR images of the entire spine of a healthy subject and is available for reuse under license [11]. This model has been used to investigate the dynamics of spinal CSF and potential for intrathecal therapy in patients with amyotrophic lateral sclerosis [12].

The removal of metabolic products and toxic substances from the brain interstitial space is important for neuronal health and a subject of intense research. Small solutes, transporter substrates and lipid soluble substances can be eliminated across the blood-brain barrier/ neurovascular unit (BBB/NVU), whereas large polar molecules including amyloid- $\beta$ may, at least in part, be eliminated via the perivascular spaces (reviewed in [13]). It has long been known that tracers in the SAS may enter brain parenchyma around penetrating blood vessels, particularly arteries/arterioles [14], although there were questions over the rate and significance of such movement [15]. Similarly, there has long been evidence that tracers placed in brain parenchyma may exit the brain to the CSF via the perivascular space [16]. Two different potential routes for fluid/solute movement around cerebral blood vessels have been identified, a space between the pia and astrocyte end feet (paravascular) and a route along the basement membranes of the smooth muscle layer (perivascular) [17-19]. This has raised many questions as to the physiological implications of these observations, not least because the movement of marker molecules does not necessarily have to occur by bulk fluid flow (convective flow). One suggestion is that CSF entering the brain via paravascular channels moves through the brain parenchyma via an astrocyte aquaporin-4 dependent pathway and clears the brain of waste products by exiting via paravenous channels (the glymphatic hypothesis [20]). However, this is still the subject of much debate $[21,22]$.

Injection of a fluorescent tracer into rat spinal cord showed that radial spread occurred within the parenchyma from grey matter into white matter but not vice versa, and most importantly tracer was seen in the paravascular spaces of arteries, arterioles and venules and also in the arterial perivascular space [23]. In the opposite direction, constriction of the rat spinal cord SAS at the cervicothoracic junction followed by intracisternal injection of fluorescent ovalbumin resulted in fluorescence in the parenchyma and also around arterioles, venules and capillaries, effects seen in control and to a greater extent in constricted animals [24]. Using data from a previous study [25] in which MR contrast agent injected intrathecally was localised in the CSF and brain by sequential imaging, convection and diffusion in the parenchyma was modelled using uncertainty quantification [26]. It was concluded that uncertainty in the diffusion coefficient was not sufficient to account for the tracer movement into white matter and that the addition of a convective velocity field (glymphatic?) may be needed to explain the data.

The evidence for fluid movement in spaces around brain vessels raises the question of the driving force, and potential mechanisms have been considered using mathematical modelling. The cardiac pulse in arterial vessels has been considered as a mechanism for propelling fluid and solutes in spaces around vessels. However, a hydraulic network model using parameters from the literature concluded that oscillatory fluid motion does not result in perivascular net flow but that solute movement may be enhanced by dispersion [27]. The hydraulic resistance of periarterial, para-arterial and para-venous channels has also been estimated using a simplified model of the cerebral vascular tree and it was concluded that the resistance was too high to allow for pressure-driven flow in any of the potential routes [18]. However, another study has shown that the shape of the periarterial space (concentric and circular or elliptical) has a large effect on the estimated hydraulic resistance and may explain some discrepancies [28]. Shear-augmented dispersion of solutes has been considered as an alternative a mechanism for solute movement using a mathematical model which takes into account the nature of the medium (porous or non-porous) and the pulsatile movement of fluids. It was concluded that such augmentation is unlikely in basement membranes but could be important in $10 \mu \mathrm{m}$ paraarterial spaces and also in the spinal SAS [29]. Readers are also referred to recent reviews that have addressed these points [30,31].

Mechanisms by which solutes move in the interstitium of the parenchyma are also a focus of much research (see recent review [32]). A hydraulic model predicted that in the parenchyma solute movement occurs largely by diffusion [27]. A different approach to estimating interstitial flow was taken by Ray et al. [33], using data from iontophoretic infusion of a small ionic molecule with concentration measurement at a known distance from the infusion. From the simulations, they concluded that both diffusion and bulk flow may be important, with bulk flow more important for large molecules. However, the calculations for flow in this study have been questioned [34] (see [35] for response). While the movement of fluid and solutes within the interstitium is important for a more complete understanding of brain physiology and pathophysiology, it may also impact drug delivery for neurological diseases. A review has considered a number of different published models for predicting drug distribution and concluded that they are incomplete. Transport 
across the $\mathrm{BBB} / \mathrm{NVU}$, movement within the brain, and molecular binding all need to be taken into account to create a 3D model that predicts drug concentration in time and space [36].

Debates over the glymphatic system and CSF production and flow have made brain fluid and solute dynamics an area of intense research. It is a very important topic influencing normal brain function and disease states, as well as drug delivery. The papers in this Thematic Series reflect that importance and the variety of approaches that are being used to address it.

\section{Author information}

Hazel C Jones is Visiting Senior Research Fellow, School of Cancer and Pharmaceutical Sciences, Faculty of Life Sciences and Medicine, King's College London, UK

\section{Acknowledgements}

None.

\section{Authors' contributions}

HCJ wrote the first draft. RFK and LRD edited the text. All authors read and approved the final manuscript.

\section{Competing interests}

HCJ, RFK and LRD are co-Editors-in-Chief of Fluids Barriers of the CNS.

\section{Author details}

${ }^{1}$ Gagle Brook House, Chesterton, Bicester OX26 1UF, UK. ${ }^{2}$ Department of Neurosurgery, University of Michigan, Ann Arbor, MI 48105, USA. ${ }^{3}$ Department of Biomedical Sciences, University of Minnesota Medical School Duluth, Duluth, MN 55812, USA.

Published online: 04 February 2020

\section{References}

1. Aktas G, Kollmeier JM, Joseph AA, Merboldt KD, Ludwig HC, Gartner J, Frahm J, Dreha-Kulaczewski S. Spinal CSF flow in response to forced thoracic and abdominal respiration. Fluids Barriers CNS. 2019;16(1):10.

2. Takizawa K, Matsumae M, Sunohara S, Yatsushiro S, Kuroda K. Characterization of cardiac- and respiratory-driven cerebrospinal fluid motion based on asynchronous phase-contrast magnetic resonance imaging in volunteers. Fluids Barriers CNS. 2017;14(1):25.

3. Hamilton RB, Scalzo F, Baldwin K, Dorn A, Vespa P, Hu X, Bergsneider M. Opposing CSF hydrodynamic trends found in the cerebral aqueduct and prepontine cistern following shunt treatment in patients with normal pressure hydrocephalus. Fluids Barriers CNS. 2019;16(1):2.

4. Takizawa K, Matsumae M, Hayashi N, Hirayama A, Yatsushiro S, Kuroda K. Hyperdynamic CSF motion profiles found in idiopathic normal pressure hydrocephalus and Alzheimer's disease assessed by fluid mechanics derived from magnetic resonance images. Fluids Barriers CNS. 2017;14(1):29.

5. Okon MD, Roberts CJ, Mahmoud AM, Springer AN, Small RH, McGregor $J M$, Katz SE. Characteristics of the cerebrospinal fluid pressure waveform and craniospinal compliance in idiopathic intracranial hypertension subjects. Fluids Barriers CNS. 2018;15(1):21.

6. Bothwell SW, Janigro D, Patabendige A. Cerebrospinal fluid dynamics and intracranial pressure elevation in neurological diseases. Fluids Barriers CNS. 2019;16(1):9.

7. Kant S, Stopa EG, Johanson CE, Baird A, Silverberg GD. Choroid plexus genes for CSF production and brain homeostasis are altered in Alzheimer's disease. Fluids Barriers CNS. 2018;15(1):34.
8. Neutzner A, Power L, Durrenberger M, Scholl HPN, Meyer P, Killer HE, Wendt D, Kohler C. A perfusion bioreactor-based 3D model of the subarachnoid space based on a meningeal tissue construct. Fluids Barriers CNS. 2019;16(1):17.

9. Benninghaus A, Baledent O, Lokossou A, Castelar C, Leonhardt S, Radermacher K. Enhanced in vitro model of the CSF dynamics. Fluids Barriers CNS. 2019;16(1):11.

10. Gehlen M, Kurtcuoglu V, Schmid Daners M. Is posture-related craniospinal compliance shift caused by jugular vein collapse? A theoretical analysis. Fluids Barriers CNS. 2017;14(1):5.

11. Sass LR, Khani M, Natividad GC, Tubbs RS, Baledent O, Martin BA. A 3D subject-specific model of the spinal subarachnoid space with anatomically realistic ventral and dorsal spinal cord nerve rootlets. Fluids Barriers CNS. 2017;14(1):36.

12. Sass LR, Khani M, Romm J, Daners MS, McCain K, Freeman T, Carter GT, Weeks DL, Petersen B, Aldred J, et al. Non-invasive MRI quantification of cerebrospinal fluid dynamics in amyotrophic lateral sclerosis patients. Fluids Barriers CNS. 2020;17(1):4. https://doi.org/10.1186/s12987-019-0164-3.

13. Hladky SB, Barrand MA. Elimination of substances from the brain parenchyma: efflux via perivascular pathways and via the blood-brain barrier. Fluids Barriers CNS. 2018;15(1):30.

14. Rennels ML, Gregory TF, Blaumanis OR, Fujimoto K, Grady PA. Evidence for a'paravascular'fluid circulation in the mammalian central nervous system, provided by the rapid distribution of tracer protein throughout the brain from the subarachnoid space. Brain Res. 1985;326(1):47-63.

15. Ichimura T, Fraser PA, Cserr HF. Distribution of extracellular tracers in perivascular spaces of the rat brain. Brain Res. 1991;545(1-2):103-13.

16. Bradbury MW, Cserr HF, Westrop RJ. Drainage of cerebral interstitial fluid into deep cervical lymph of the rabbit. Am J Physiol. 1981;240(4):F329-36.

17. Bakker EN, Bacskai BJ, Arbel-Ornath M, Aldea R, Bedussi B, Morris AW, Weller RO, Carare RO. Lymphatic clearance of the brain: perivascular, paravascular and significance for neurodegenerative diseases. Cell Mol Neurobiol. 2016;36(2):181-94.

18. Faghih MM, Sharp MK. Is bulk flow plausible in perivascular, paravascular and paravenous channels? Fluids Barriers CNS. 2018;15(1):17.

19. Hladky SB, Barrand MA. Mechanisms of fluid movement into, through and out of the brain: evaluation of the evidence. Fluids Barriers CNS. 2014;11(1):26

20. Iliff JJ, Wang M, Liao Y, Plogg BA, Peng W, Gundersen GA, Benveniste $H$, Vates GE, Deane R, Goldman SA, et al. A paravascular pathway facilitates CSF flow through the brain parenchyma and the clearance of interstitial solutes, including amyloid beta. Sci Transl Med. 2012:4(147):147ra111.

21. Abbott NJ, Pizzo ME, Preston JE, Janigro D, Thorne RG. The role of brain barriers in fluid movement in the CNS: is there a'glymphatic' system? Acta Neuropathol. 2018;135(3):387-407.

22. Rasmussen $M K$, Mestre $H$, Nedergaard $M$. The glymphatic pathway in neurological disorders. Lancet Neurol. 2018;17(11):1016-24.

23. Liu S, Lam MA, Sial A, Hemley SJ, Bilston LE, Stoodley MA. Fluid outflow in the rat spinal cord: the role of perivascular and paravascular pathways. Fluids Barriers CNS. 2018;15(1):13.

24. Berliner JA, Woodcock T, Najafi E, Hemley SJ, Lam M, Cheng S, Bilston LE, Stoodley MA. Effect of extradural constriction on CSF flow in rat spinal cord. Fluids Barriers CNS. 2019;16(1):7.

25. Ringstad G, Vatnehol SAS, Eide PK. Glymphatic MRI in idiopathic normal pressure hydrocephalus. Brain. 2017;140(10):2691-705.

26. Croci M, Vinje V, Rognes ME. Uncertainty quantification of parenchymal tracer distribution using random diffusion and convective velocity fields. Fluids Barriers CNS. 2019;16(1):32.

27. Rey J, Sarntinoranont M. Pulsatile flow drivers in brain parenchyma and perivascular spaces: a resistance network model study. Fluids Barriers CNS. 2018;15(1):20.

28. Tithof J, Kelley DH, Mestre H, Nedergaard M, Thomas JH. Hydraulic resistance of periarterial spaces in the brain. Fluids Barriers CNS. 2019;16(1):19.

29. Keith Sharp M, Carare RO, Martin BA. Dispersion in porous media in oscillatory flow between flat plates: applications to intrathecal, periarterial and paraarterial solute transport in the central nervous system. Fluids Barriers CNS. 2019;16(1):13.

30. Martinac AD, Bilston LE. Computational modelling of fluid and solute transport in the brain. Biomech Model Mechanobiol. 2019. https://doi. org/10.1007/s10237-019-01253-y. 
31. Thomas JH. Fluid dynamics of cerebrospinal fluid flow in perivascular spaces. J R Soc Interface. 2019;16(159):20190572.

32. Chatterjee K, Carman-Esparza CM, Munson JM. Methods to measure, model and manipulate fluid flow in brain. J Neurosci Methods. 2019;333:108541.

33. Ray L, lliff JJ, Heys JJ. Analysis of convective and diffusive transport in the brain interstitium. Fluids Barriers CNS. 2019;16(1):6.

34. Hladky SB, Barrand MA. Is solute movement within the extracellular spaces of brain gray matter brought about primarily by diffusion or flow? A commentary on "Analysis of convective and diffusive transport in the brain interstitium" Fluids and Barriers of the CNS (2019) 16:6 by L. Ray, J.J. Iliff and J.J. Heys. Fluids Barriers CNS 2019;16(1):24.
35. Ray L, Iliff JJ, Heys JJ. In response to "Is solute movement within the extracellular spaces of brain gray matter brought about primarily by diffusion or flow?". Fluids Barriers CNS. 2019;16(1):23.

36. Vendel $E$, Rottschafer $V$, de Lange ECM. The need for mathematical modelling of spatial drug distribution within the brain. Fluids Barriers CNS. 2019;16(1):12

\section{Publisher's Note}

Springer Nature remains neutral with regard to jurisdictional claims in published maps and institutional affiliations.
Ready to submit your research? Choose BMC and benefit from:

- fast, convenient online submission

- thorough peer review by experienced researchers in your field

- rapid publication on acceptance

- support for research data, including large and complex data types

- gold Open Access which fosters wider collaboration and increased citations

- maximum visibility for your research: over $100 \mathrm{M}$ website views per year

At BMC, research is always in progress.

Learn more biomedcentral.com/submissions 